\title{
LT GAME 20 SEBAGAI MEDIA PEMBELAJARAN INTERAKTIF PADA MATERI LIMIT TRIGONOMETRI
}

\author{
Binti Anisaul Khasanah $^{1)}$, Imam Nurohim ${ }^{2)}$, Zulfa Taufiqoh ${ }^{3)}$, Sigit Waluyo ${ }^{4)}$ \\ ${ }^{1), 2), 3), 4)}$ Pendidikan Matematika, Universitas Muhammadiyah Pringsewu Lampung \\ Email : ${ }^{1}$ bintianisaul@ umpri.ac.id \\ 2)imam.17030010@student.umpri.ac.id \\ 3) zulfa.18030028@student.umpri.ac.id \\ 4) sigit.2019406402003@student.umpri.ac.id
}

\begin{abstract}
Abstrak
Pemasalahan dalam penelitian ini adalah peseta didik yang selalu kesulitan untuk menyelesaikan soal yang bervariasi pada materi Limit Trigonometri yang merupakan gabungan antara konsep Kalkulus dan Trigonometri. Hal ini mendorong peneliti untuk membuat media pembelajaran yang cocok diterapkan kepada peserta didik sebagai media pembelajaran interaktif yang berisikan tantangan untuk menyelesaikan permasalahan melaui game pada materi Limit Trigonometri. Adapun tujuan yang hendak peneliti capai yaitu dengan mengembangkan dan menghasilkan produk berupa game edukasi media pembelajaran interktif tentang Limit Trigonometri. Metode penelitian ini menggunakan metode Research and Development. Hasil penelitian yang telah didapatkan adalah menghasilkan produk game edukasi pada materi Limit Trigonometri dengan hasil validasi yang baik atau layak digunakan dan hasil uji coba aplikasi sudah berfungsi dan berjalan dengan baik. Hal ini dapat disimpulkan game edukasi media pembelajaran interktif tentang Limit Trigonometri layak dan efektif sebagai media pembelajaran interakif yang dapat digunakan oleh peserta didik untuk lebih memahami limit trigonometri dengan cara yang menyenangkan.
\end{abstract}

Kata kunci: Media Pembelajaran, Game Edukasi, Limit Trigonometri

\begin{abstract}
The problem in this study is that students always have difficulty solving various problems on Trigonometric Limit which is a combination of the concepts of Calculus and Trigonometry. This encourages researchers to make learning media suitable for students as interactive learning media that contains challenges to solve problems through games on Trigonometric Limit material. The goal that the researchers want to achieve is to develop and produce products in the form of educational games for interactive learning media about Trigonometric Limits. This research method uses the Research and Development method. The results of the research that have been obtained are to produce educational game products on Trigonometric Limit material with good validation results or suitable for use and the results of the application trial are functioning and running well. It can be concluded that interactive learning media educational games about Trigonometric Limits are feasible and effective as interactive learning media that can be used by students to better understand trigonometric limits in a fun way.
\end{abstract}

.Keywords: Learning Media, Educational Games, Limit Trigonometry

\section{PENDAHULUAN}

Matematika merupakan ilmu pasti yang bersifat abstrak, sehingga diperlukan adanya media pembelajaran untuk membantu menjelaskan konsep - konsep secara sederhana dan mudah dipahami. Media pembelajaran merupakan wahana penyalur pesan dan informasi belajar, 


\section{LT Game 20 Sebagai Media Pembelajaran Interaktif}

media pembelajaran yang dirancang secara baik akan sangat membantu peserta didik dalam mencerna dan memahami materi pelajaran (Muhson, 2010). Penggunaan media pembelajaran dapat mengubah pembelajaran matematika yang abstrak menjadi menyenangkan (Khairani, Febrinal, 2016).

Pada jenjang sekolah menengah atas pembelajaran matematika maliputi aljabar, geometri, bangun datar, bangun ruang, trigonometri dan kalkulus. Salah satu materi yang selalu sulit dipahami oleh peserta didik adalah limit trigonometri yang merupakan gabungan konsep kalkulus dan trigonometri. Variasi soal tentang limit trigonometri sangat beragam.

Dari beragamnya variasi soal tersebut, kesulitan peserta didik dalam memahami limit trigonometri dapat diatasi dengan cara meningkatkan pemahamannya melalui metode drill yaitu dengan banyak mengerjakan soal-soal latihan. Hal ini sesuai dengan penelitian yang dilakukan Juniati bahwa metode drill dapat memberikan sumbangan yang sangat tepat bagi siswa, hal ini dapat diketahui dari data kenaikan atau peningkatan nilai yang didapat siswa dari tahapan per siklusnya mengalami perbedaan yang signifikan (Juniati, 2017).

Mengacu pada hal tersebut dan observasi terhadap minat belajar yang pada era milenial sekarang yang digandrungi adalah media berbasis Ilmu Teknologi (IT). Oleh karena itu, penulis menyusun sebuah media pembelajaran yang menggabungkan kedua hal tersebut yang tercakup dalam media pembelajaran interaktif yaitu $L T$ Game 20. Media pembelajaran LT Game 20 merupakan media pembelajaran interaktif tentang materi Limit Trigonometri dengan konsep game, yang didalamnya terdapat levellevel dalam bentuk soal yang harus diselesaikan. Pemilihan konsep game ini memiliki tujuan agar siswa dalam melatih kemampuannya menyelesaikan soal-soal melalui metode latihan dapat dilalui dalam suasana yang menyenangkan. Siswa yang belajar dengan bermain game membuat mereka lebih antusias, relaks, senang dan nyaman dalam mengikuti pembelajaran (joyful learning) (Heriyanto et al., 2014). Adanya tantangan untuk maju ke level selanjutnya pada game ini dengan cara mengerjakan soal- soal yang sudah disiapkan dengan benar, peserta didik akan lebih tertarik dan semangat dalam belajar dan berlatih menyelesaikan soal-soal yang berkaitan dengan limit trigonometri.

Media pembelajaran adalah bagian dari sumber belajar yang merupakan kombinasi antara perangkat lunak (bahan belajar) dan perangkat keras (alat belajar) (Muhson, 2010). Secara harfiah istilah 
media berasal dari bahasa Latin yang merupakanbentuk jamak dari "medium" yang berarti perantara atau pengantar. Secara umum makna media adalah segala sesuatu yang dapat diguanakan untuk menyalurkan informasi dari informan kepada penerima informasi. Proses pembelajaran dikelas pada dasarnya juga merupakan proses komunikasi, sehingga media yang digunakan dalam pembelajaran disebut media pembelajaran. Media pembelajaran merupakan suatu teknologi pembawa pesan yang dapat digunakan untuk sarana pembelajaran, media pembelajaran merupakan saran fisik untuk menyampaikan materi pembelajaran (Rusman, 2012). Media dapat digunakan sebagai pengarah atau pemberi pesan dalam pembelajaran, sebagai pembangkit perhatian, motivasi siswa serta gairah belajar melalui interaksi lebih langsung antara siswa dengan sumber belajar (Heriyanto et al., 2014).

Game merupakan salah satu wujud nyata dari pemanfaatan kecanggihan teknologi. Game jika diartikan secara bahasa (berasal dari bahasa Inggris) adalah permainan. Dengan bantuan teknologi kini game dapat diartikan sebagai permainan yang diprogram pada suatu perangkat yang dapat dijalankan secara offline dan secara online. Game merupakan kegiatan yang melibatkan keputusan pemainnya untuk mencapai tujuan dalam game dengan dibatasi oleh konteks-konteks tertentu (Clark, 2006). Nilai positif yang sebenarnya ada terkandung dalam game seringkali tidak disadari oleh pengguna (siswa). Padahal pecandu game sebagian besar siswa SMA, SMK sederajat, sehingga selain sebagai hiburan, game juga bias dijadikan alat komunikasi dan teman belajar siswa yang menghibur dan menyenangkan (Setiawan, Wiyardi, 2015). Game memiliki hubungan yang sangat erat dan berpengaruh positif dalam proses pembelajaran (Pelletiere, 2009). Game dengan tujuan pembelajaran biasanya disebut dengan game edukasi.

LT (Limit Trigonometri) Game 20 adalah sebuah media pembelajaran tentang Limit Trigonometri yang dibuat dengan software Adobe Flash dengan konsep game yang didalamnya terdapat level-level yang harus diselesaikan. Bilangan 20 dibelakang kata LT Game adalah bilangan yang menunjukan banyaknya level yang disediakan di LT Game 20 yaitu 20 (dua puluh) level. Adapun tampilan dari LT Game 20 sebagai berikut: 


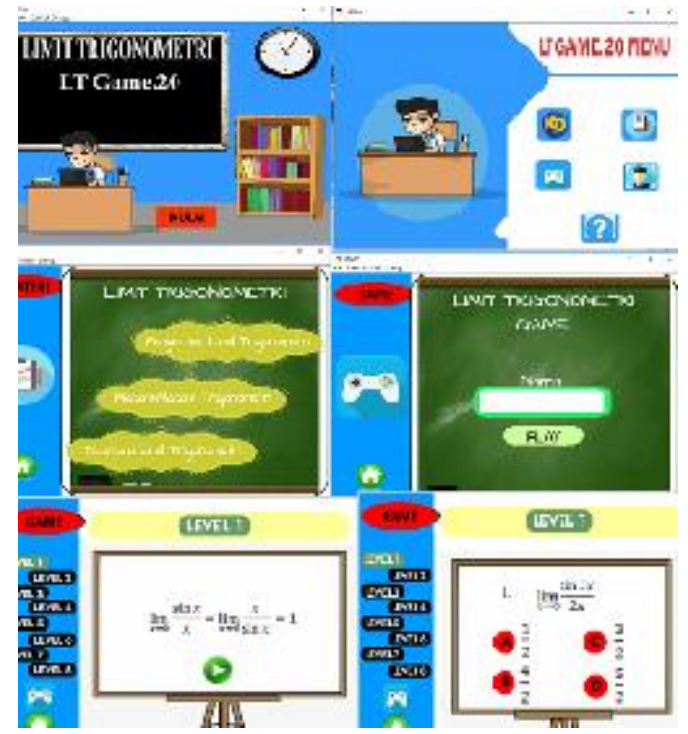

Gambar 1. Tampilan LT Game 20

\section{METODE PENELITIAN}

Penelitian bertujuan untuk untuk mengetahui pengembangan LT Game 20 sebagai media pembelajaran interaktif dan mengetahui apakah LT Game 20 layak digunakan sebagai media pembelajaran interaktif pada materi limit trigonometri.

Penelitian ini merupakan jenis penelitian Research and Development $(R n D)$ atau sering dikenal dengan istilah penelitian pengembangan. Metode penelitian dan pengembangan merupakan metode penelitian yang digunakan untuk menghasilkan produk tertentu dan menguji keefektifan produk tersebut (Sugiyono, 2013). penelitian dan pengembangan mencakup serangkaian tahap kegiatan pengembangan produk, uji coba produk, dan tahap revisi produk (Borg dan Gall dalam Haji, 2011). Penelitian pengembangan juga merupakan metode penelitian untuk menyelidiki pola dan perurutan pertumbuhan dan atau perubahan sebagai fungsi waktu (Suryabrata, 2012). Penelitian ini akan mengembangkan media pembelajaran interaktif pada materi limit trigonometri yang diberi nama LT game 20. Sebelum digunakan dikembangkan dengan memperhatikan prosedur research and development (R\&D). Berikut langkahlangkah pengembangan LT game 20:

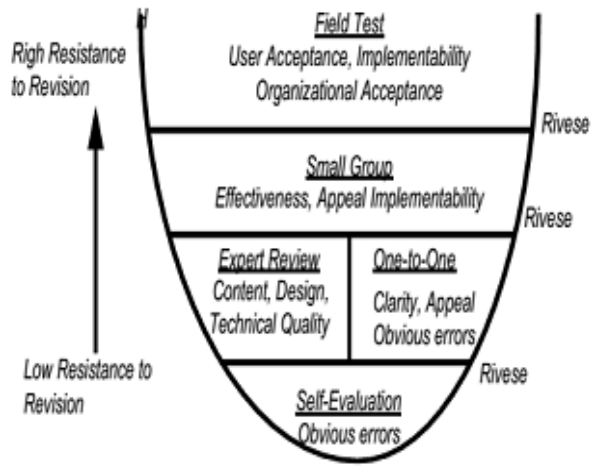

Gambar 2. Alur desain penelitian

Prosedur penelitian ini dibagi dalam 4 tahapan, yaitu meliputi :

\section{a. Self Evaluation}

\section{1) Analisis}

Tahap ini merupakan tahap dimana peneliti melakukan analisis terhadap permasalahan peserta didik dan permasalahannya

\section{2) Desain}

Tahap desain yang dimaksud adalah mengembangkan media interaktif LT game 20. Produk awal dinamakan prototipe pertama. Adapun penelitian ini 
menghasilkan tiga prototipe yaitu prototipe pertama (hasil self evaluation), prototipe kedua (revisi dari expert review dan one-to-one) dan prototipe ketiga sebagai prototipe akhir (revisi dari small group), dimana masing-masing prototipe fokus pada tiga karakteristik yaitu: conten, konstruks dan bahasa.

\section{b. Expert Review dan One-to-one evaluation}

Hasil desain pada prototipe pertama yang dikembangkan atas dasar self evaluation diberikan pada pakar (expert review) dan tiga orang peserta didik (one-to-one) untuk mengamati, mengkomentari, dan memberikan saran.

1) Uji Pakar (expert judgement)

Pada tahap uji pakar, game yang telah dibuat akan dicermati, dinilai dan dievaluasi oleh para ahli yang terdiri dari tiga orang dalam bidang ilmu pendidikan matematika sebagai ahli materi dan tiga orang dalam bidang IT sebagai ahli media.

2) One-to-one

Pada tahap one-to-one, peneliti memanfaatkan tiga orang sebagai testee dan diminta untuk mengamati, mengkomentari game yang dibuat. Hasil komentar tersebut akan dijadikan dasar untuk merevisi game yang dibuat. Hasil uji pakar (expert judgement) dan one-to-one menjadi dasar untuk merevisi LT game 20 yang dibuat (prototipe pertama). Hasil revisi dari uji pakar (expert judgement) dan one-to-one menghasilkan prototipe kedua.

\section{c. Small Group (kelompok kecil)}

Hasil prototipe kedua diujicobakan pada lima orang peserta didik non subjek penelitian. Hasil dari uji small group akan dijadikan dasar untuk merevisi LT game 20 prototipe kedua. Hasil revisi tersebut dinamakan prototipe ketiga (produk).

\section{d. Field Test (Uji lapangan )}

Pada pelaksanaan field test, prototipe ketiga (produk) diujikan ke subjek penelitian.

Kelayakan media pembelajaran interaktif LT game 20 dibuat persentase kemudian dikonversikan dengan kriteria deskriptif kelayakan media pada table berikut:

Tabel 1. Kriteria deskriptif persentase kelayakan LT game 20

\begin{tabular}{cc}
\hline Interval $(\%)$ & Kriteria \\
\hline $81-100$ & Sangat Layak \\
$61-80$ & Layak \\
$41-60$ & Cukup Layak \\
$21-40$ & Kurang Layak \\
$0-20$ & Tidak Layak \\
\hline
\end{tabular}

(Heriyanto et al., 2014).

Data hasil tes siswa dianalisis kemudian dibandingkan dengan nilai Kriteria Ketuntasan Minimal (KKM) yang telah ditetapkan. Seorang siswa dikatakan tuntas jika siswa tersebut memperolehnilai $\geq 72$ sebagai Kriteria Ketuntasan Minimal (KKM). Sedangkan jika $85 \%$ siswa memenuhi kriteria tuntas 
maka rata-rata skor tes hasil belajar siswa memenuhi ketuntasan klasikal yang mana ini berarti bahwa LT game 20 dapat dikatakan efektif sebagai media pembelajaran interaktif pada materi limit trigonometri (Mulyasa, 2007).

\section{HASIL DAN PEMBAHASAN}

Hasil pengembangan pada penelitian ini berupa media pembelajaran interaktif pada materi limit trigonometri yang diberi nama LT game 20. Penelitian dan pengembangan ini dilakukan dalam 4 tahapan sebagai berikut:

\section{a. Self Evaluation}

1) Analisis

Berdasarkan analisis yang dilakukan peneliti terhadap materi limit trigonometri, terdapat permasalahan berupa soal yang bervariasi dan membutuhkan keterampilan dan kemampuan untuk menyelesaikannya secara tepat. Untuk memperoleh keterampilan dan kemampuan tersebut diperlukan banyak latihan dalam mengerjakan soal-soal yang beragam. Agar siswa tidak bosan dalam mengerjakan soal maka diperlukan media yang menyenangkan seperti game.

2) Desain

Tahap desain yang dimaksud adalah membuat dan mengembangkan media pembelajaran interaktif pada materi limit trigonometri yaitu LT game 20.

\section{b. Expert Review dan One-to-one evaluation}

Hasil pengembangan LT game 20 pada prototipe pertama yang dikembangkan atas dasar self evaluation diberikan pada pakar (expert review) yang terdiri dari ahli media dan ahli materi serta tiga orang peserta didik (one-to-one) untuk mengamati, mengomentari, dan memberikan saran.

1) Uji Pakar (expert judgement)

Hasil prototipe pertama diberikan kepada para pakar yaitu ahli media yang terdiri dari: Susilo Hartono, S.T, M.T.I. selaku validator ahli media pertama, Bambang Triraharjo. S. Kom., M.T.I. selaku validator ahli media kedua, dan Roby Novianto,S.T, M.T.I. selaku validator ahli media ketiga. Uji validitas media LT game 20 dilihat dari aspek tampilan dan pemrograman dengan hasil validasi sebagai berikut:

Tabel 2. Hasil Validasi Ahli Media Pembelajaran Aspek Tampilan

\begin{tabular}{|c|c|c|c|c|}
\hline $\begin{array}{l}\mathbf{N} \\
\mathbf{o}\end{array}$ & Kritera & & $\bar{X}_{j}$ & ${\underset{(\%)}{P}}^{P_{0}}$ \\
\hline & Kualitas Grafis & & 3,9 & 79 \\
\hline 1 & $\begin{array}{l}\text { Tata letak teks dan } \\
\text { gambar pada media } \\
\text { pembelajaran }\end{array}$ & 4 & & \\
\hline 2 & $\begin{array}{l}\text { Kesesuaian pemilihan } \\
\text { background }\end{array}$ & 4 & & \\
\hline 3 & $\begin{array}{l}\text { Kesesuaian pemilihan } \\
\text { ukuran dan jenis huruf }\end{array}$ & 4,7 & & \\
\hline 4 & Kesesuaian warna & 4,3 & & \\
\hline 5 & $\begin{array}{l}\text { Kemenarikan } \\
\text { gambar animasi }\end{array}$ & 4 & & \\
\hline 6 & $\begin{array}{l}\text { Kesesuaian pemilihan } \\
\text { gambar animasi dengan }\end{array}$ & 3,7 & & \\
\hline
\end{tabular}




\begin{tabular}{|c|c|c|c|c|}
\hline $\begin{array}{l}\mathbf{N} \\
\mathbf{o}\end{array}$ & Kritera & $\overline{\boldsymbol{X}}_{\boldsymbol{i}}$ & $\bar{X}_{j}$ & $\begin{array}{l}\mathbf{P}_{(\%)} \\
\end{array}$ \\
\hline & materi & & & \\
\hline & Kualitas Tombol & & 4,2 & 83 \\
\hline 7 & $\begin{array}{l}\text { Kemenarikan tampilan } \\
\text { tombol }\end{array}$ & 4 & & \\
\hline 8 & $\begin{array}{lr}\text { Keteraturan } & \text { dan } \\
\text { konsistensi } & \text { tampilan } \\
\text { tombol } & \end{array}$ & 4,3 & & \\
\hline & Total Skor & 32 & 32 & 80 \\
\hline
\end{tabular}

Tabel 2 menunjukkan bahwa LT game 20 memenuhi kriteria layak dilihat dari aspek tampilan yaitu dengan presentase kelayakan $80 \%$.

Tabel 3. Hasil Validasi Ahli Media Pembelajaran Aspek Pemrograman

\begin{tabular}{|c|c|c|c|c|}
\hline $\begin{array}{l}\mathrm{N} \\
\mathrm{o}\end{array}$ & Kritera & $\bar{X}_{i}$ & $\bar{X}_{j}$ & $\begin{array}{l}\mathrm{P} \\
(\%)\end{array}$ \\
\hline & Efisiensi Media & & 4,2 & 83,3 \\
\hline 1 & $\begin{array}{l}\text { Kemudahan pemakaian } \\
\text { program }\end{array}$ & 4 & & \\
\hline 2 & $\begin{array}{l}\text { Kemudahan memilih } \\
\text { menu program }\end{array}$ & 4,3 & & \\
\hline 3 & $\begin{array}{l}\text { Kemudahan } \\
\text { berinteraksi dengan } \\
\text { program }\end{array}$ & 3,7 & & \\
\hline 4 & $\begin{array}{l}\text { Kemudahan masuk dan } \\
\text { keluar dari program }\end{array}$ & 4,7 & & \\
\hline & Fungsi Tombol & & 4,2 & 83,3 \\
\hline 5 & $\begin{array}{l}\text { Kemudahan memahami } \\
\text { struktur tombol }\end{array}$ & 4,3 & & \\
\hline 6 & $\begin{array}{l}\text { Ketepatan reaksi } \\
\text { tombol. }\end{array}$ & 4 & & \\
\hline & Kualitas Fisik & & 4,3 & 86,7 \\
\hline 7 & $\begin{array}{l}\text { Kapasitas file program } \\
\text { untuk kemudahan } \\
\text { duplikasi/penggandaan }\end{array}$ & 4,3 & & \\
\hline 8 & $\begin{array}{l}\text { Kekuatan/keawetan } \\
\text { program }\end{array}$ & 4,3 & & \\
\hline & Total Skor & 33,7 & 33,7 & 84,2 \\
\hline
\end{tabular}

Tabel 3 menunjukkan bahwa LT game 20 memenuhi kriteria sangat layak dilihat dari aspek pemrogaman yaitu dengan presentase kelayakan $84,2 \%$.
Hasil prototipe pertama juga diberikan kepada para pakar yaitu ahli materi yang terdiri dari tiga dosen FKIP prodi pendidikan matematika yaitu: Siti Rahayu, M.Pd. selaku validator pertama, Ari Suningsih, M.Pd. selaku validator kedua, dan Rahman Cahyadi S.Pd., M.Si. selaku validator ketiga. Hasil validasi oleh ahli materi media LT game 20 disajikan pada tabel berikut:

Tabel 4 Hasil Validasi Ahli Materi

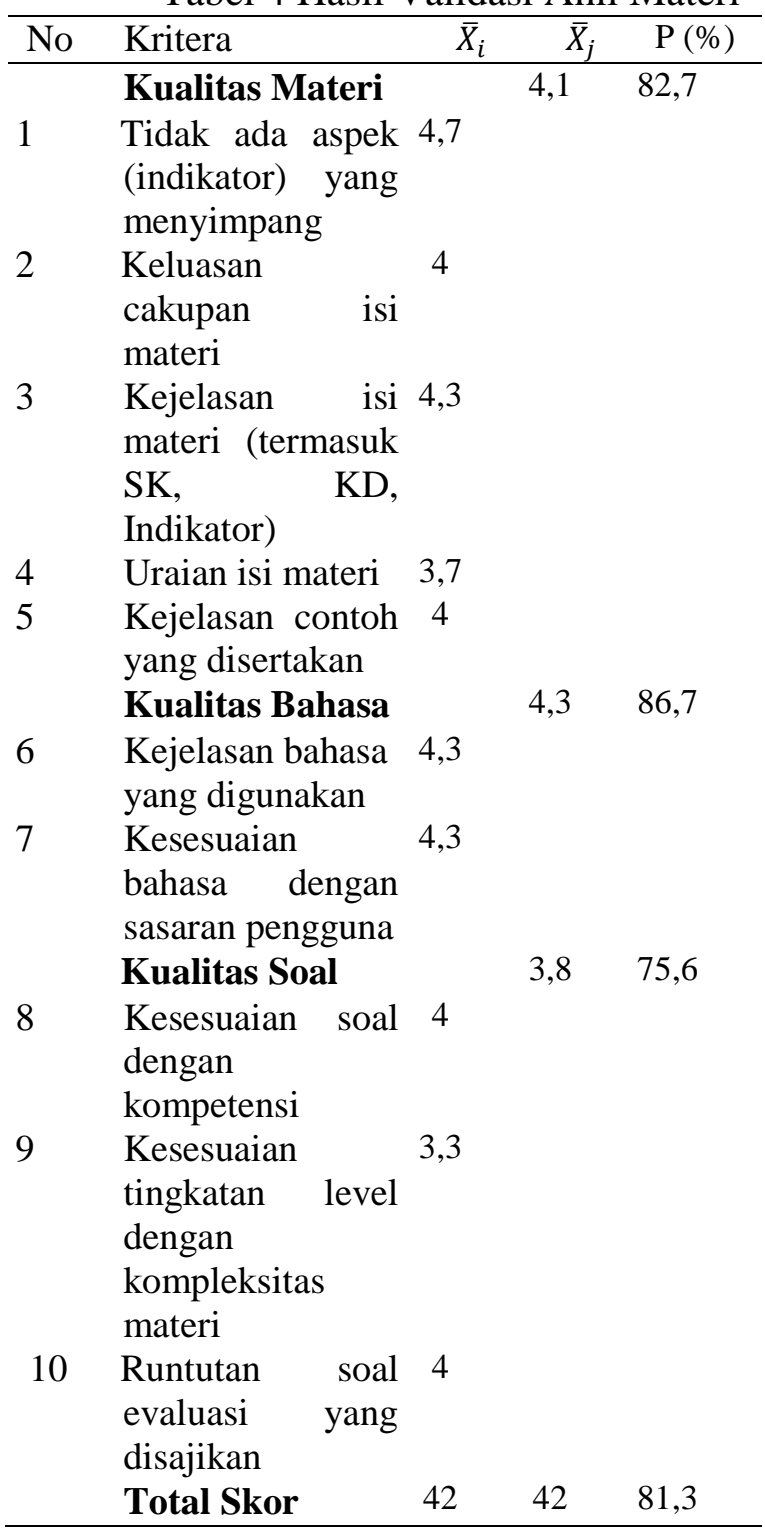


Tabel 4 menunjukkan bahwa LT game 20 memenuhi kriteria sangat layak dilihat dari aspek materi yaitu dengan presentase kelayakan $81,3 \%$.

2) One-to-one

Pada tahap one-to-one, peneliti meminta tiga orang siswa sebagai testee dan diminta untuk mengamati, mengkomentari game yang dibuat denga cara mengisi angket respon siswa yang disediakan. Hasil dari tahap one-to-one disajikan pada tabel berikut:

Tabel 5 Hasil Analisis Angket Respon Siswa Tahap One-to-one

\begin{tabular}{|c|c|c|c|c|}
\hline No & Kritera & $\overline{\boldsymbol{X}}_{\boldsymbol{i}}$ & $\bar{X}_{j}$ & $\begin{array}{l}P \\
(\%)\end{array}$ \\
\hline & Aspek & & 4,7 & 93 \\
\hline & Pemrograman & & & \\
\hline 1 & $\begin{array}{l}\text { Kemudahan } \\
\text { pemakaian media }\end{array}$ & 4,7 & & \\
\hline 2 & $\begin{array}{l}\text { Kemudahan } \\
\text { memilih menu } \\
\text { program }\end{array}$ & 4,7 & & \\
\hline 3 & $\begin{array}{l}\text { Kemudahan } \\
\text { masuk dan keluar } \\
\text { dari program }\end{array}$ & 5 & & \\
\hline 4 & $\begin{array}{l}\text { Ketepatan reaksi } \\
\text { tombol }\end{array}$ & 4,3 & & \\
\hline & Aspek Isi & & & \\
\hline 5 & $\begin{array}{l}\text { Kejelasan bahasa } \\
\text { yang digunakan }\end{array}$ & 4 & & \\
\hline 6 & $\begin{array}{l}\text { Tidak ada } \\
\text { kata/kalimat yang } \\
\text { menyimpang }\end{array}$ & 4 & & \\
\hline 7 & $\begin{array}{l}\text { Contoh soal } \\
\text { sesuai dengan } \\
\text { materi yang } \\
\text { disampaikan }\end{array}$ & 3,7 & & \\
\hline 8 & $\begin{array}{l}\text { Melalui media ini } \\
\text { Anda mudah } \\
\text { memahami materi } \\
\text { pembelajaran }\end{array}$ & 4,3 & & \\
\hline 9 & $\begin{array}{l}\text { Urutan isi materi } \\
\text { sesuai indikator }\end{array}$ & 3,7 & & \\
\hline 10 & Contoh-contoh & 4 & & \\
\hline
\end{tabular}

\begin{tabular}{|c|c|c|c|c|}
\hline No & Kritera & $\overline{\boldsymbol{X}}_{\boldsymbol{i}}$ & $\bar{X}_{j}$ & $\begin{array}{l}\mathbf{P} \\
(\%)\end{array}$ \\
\hline & dalam soal jelas & & & \\
\hline 11 & $\begin{array}{l}\text { Bahasa yang } \\
\text { digunakan mudah } \\
\text { dipahami dan } \\
\text { komunikatif }\end{array}$ & 4 & & \\
\hline 12 & $\begin{array}{l}\text { Soal yang } \\
\text { diberikan sesuai } \\
\text { dengan }\end{array}$ & 3,3 & & \\
\hline & kemampuan Anda & & & \\
\hline \multirow[t]{3}{*}{13} & $\begin{array}{l}\text { Soal evaluasi } \\
\text { yang }\end{array}$ & 4 & & \\
\hline & $\begin{array}{l}\text { diberikan/sajikan } \\
\text { berurutan sesuai } \\
\text { dengan indikator } \\
\text { materi pelajaran }\end{array}$ & & & \\
\hline & Aspek Tampilan & & 4,5 & 90 \\
\hline 14 & $\begin{array}{l}\text { Tata letak teks } \\
\text { dan gambar }\end{array}$ & 4,3 & & \\
\hline 15 & $\begin{array}{l}\text { Kesesuaian } \\
\text { pemilihan } \\
\text { background }\end{array}$ & 4,3 & & \\
\hline 16 & Kesesuaian warna & 4,7 & & \\
\hline 17 & $\begin{array}{l}\text { Kesesuaian } \\
\text { pemilihan ukuran } \\
\text { dan jenis huruf }\end{array}$ & 4,7 & & \\
\hline 18 & $\begin{array}{l}\text { Kesesuaian } \\
\text { gambar animasi } \\
\text { yang disajikan }\end{array}$ & 4,7 & & \\
\hline 19 & $\begin{array}{l}\text { Kemenarikan } \\
\text { tampilan tombol } \\
\text { yang digunakan }\end{array}$ & 4,3 & & \\
\hline \multirow[t]{3}{*}{20} & Kemenarikan & 4,3 & & \\
\hline & $\begin{array}{l}\text { gambar animasi } \\
\text { yang digunakan }\end{array}$ & & & \\
\hline & Total Skor & 85 & 85 & 85 \\
\hline
\end{tabular}

Tabel 5 menunjukkan bahwa LT game 20 memenuhi kriteria sangat layak dilihat dari respon siswa pada tahap one-to-one yaitu dengan persentase kelayakan $85 \%$. Berdasarkan uji pakar dan uji tahap one-toone diperoleh bahwa LT game 20 memenuhi kriteria laya dan sangat layak. Dengan demikian, LT game 20 dapat dilanjutkan ke prototipe kedua. 


\section{c. Small Group (kelompok kecil)}

Hasil prototipe kedua diujicobakan pada lima orang peserta didik non subjek penelitian kemudian responden diminta untuk mengisi angket respon siswa. Hasil analisis angket respon siswa pada kelompok kecil dapat dilihat pada tabel berikut:

Tabel 6. Hasil Analisis Angket Respon Siswa pada Kelompok Kecil

\begin{tabular}{llll}
\hline No & Kriteria & $P_{i}(\%)$ & $P_{j}(\%)$ \\
\cline { 1 - 2 } 1 & Aspek Pemrograman & 82 & \multirow{2}{*}{82} \\
\cline { 1 - 2 } 2 & Aspek Isi & 83 & \\
\cline { 1 - 2 } 3 & Aspek Tampilan & 82 & \\
\hline
\end{tabular}

Tabel 6 menunjukkan bahwa LT game 20 memenuhi kriteria sangat layak dilihat dari respon siswa pada kelompok kecil yaitu dengan persentase kelayakan $82 \%$. Berdasarkan hasil analisis tersebut maka LT game 20 dapat dilanjutkan ke prototipe ketiga dan siap diujicobakan.

\section{d. Field Test (Uji lapangan )}

Hasil dari prototipe ketiga (produk) diujikan ke subjek penelitian yaitu siswa SMA Negeri 2 Pringsewu yang dipilih sampel sebanyak 15 siswa dengan teknik simple random sampling. Berdasarkan hasil uji lapangan diperoleh data tentang respon siswa terhadap LT game 20 dan hasil tes siswa pada materi limit trigonometri.
Tabel 7. Hasil Analisis Angket Respon Siswa pada Uji Lapangan

\begin{tabular}{llll}
\hline No & Kriteria & $P_{i}(\%)$ & $P_{j}(\%)$ \\
\hline 1 & Aspek Pemrograman & 81 & \multirow{2}{*}{81} \\
\cline { 1 - 2 } 2 & Aspek Isi & 81 & \\
\cline { 1 - 3 } 3 & Aspek Tampilan & 81 & \\
\hline
\end{tabular}

Tabel 7 menunjukkan bahwa LT game 20 memenuhi kriteria sangat layak dilihat dari respon siswa pada uji lapangan yaitu dengan persentase kelayakan $81 \%$. Sedangkan berdasarkan data hasil tes siswa pada materi limit trigonometri diperoleh bahwa siswa yang tuntas dengan nilai mencapai KKM ada 13 siswa atau 86\%. Dengan demikian dapat disimpulkan bahwa game edukasi media pembelajaran interktif tentang Limit Trigonometri yaitu LT game 20 layak dan efektif sebagai media pembelajaran interakif.

\section{SIMPULAN}

Berdasarkan hasilpenelitian yang telah dilakukan maka dapat disimpulkan bahwa:

1. Pengembangan LT game 20 sebagai media media pembelajaran interktif pada materi Limit Trigonometri melalui empat tahap yaitu: Self Evaluation, Expert Review dan One-toone evaluation, Small Group (kelompok kecil), dan Field Test (Uji lapangan). 
2. LT game 20 layak digunakan sebagai media media pembelajaran interktif pada materi Limit Trigonometri.

\section{DAFTAR PUSTAKA}

Clark, D 2006, Game and E-learning, Caspian Learning, Sunderland.

Haji, S 2011, 'Model Bahan Ajar Matematika Smp Berbasis Realistic Mathematics Education Untuk Mengembangkan Kemahiran Matematika', Jurnal Exacta, vol. 9, no. 1, hh. 46.

Heriyanto, A, Haryani, S\& Sedyawati, SMR 2014 ' Pengembangan Multimedia Pembelajaran Interaktif Berbasis Education Game Sebagai Media Pembelajaran Kimia', Chemistry in Education, vol. 3, no. 1, hh. 1-7.

Juiati, E 2017 ' Peningkatkan Hasil Belajar Matematika Melalui Metode Drill dan Diskusi Kelompok pada Siswa Kelas VI SD', Scholaria: Jurnal Pendidikan dan Kebudayaan, vol. 7, no. 3, hh. 283-291.

Khairani, M Febrinal, D 2016, Pengembangan Media Pembelajaran dalam Bentuk Macromedia Flash Materi Tabung untuk SMP Kelas IX, JURNAL IPTEKS TERAPAN: Research of Applied Science and Education, Vol. 10, no.2, hh. 95-102.

Muhson, A 2010 ' Pengembangan Media Pembelajaran Berbasis Teknologi Informasi', Jurnal Pendidikan Akuntansi Indonesia, vol. 8, no. 2, hh. $1-10$.

Mulyasa, E 2007, Standar Kompetensi dan Sertifikasi Guru, Rosdakarya, Bandung.
Pelletiere, C 2009, 'Games and Learning', International Journal of Learning and Media. vol. 1, no. 1, hh. 84-100.

Rusman 2012, Pembelajaran Berbasis Teknologi Informasi dan Komunikasi, Rajawali Pers, Jakarta.

Setiawan, HW Wiyardi, RS 2015, 'Penggunaan APP Inventor dalam Pembuatan Game Education Berbasis Android sebagai Media Pembelajaran yang Mandiri dan Interaktif untuk Meningkatkan Hasil Belajar Siswa TITL pada Pembelajaran Listrik Dasar SMK Muhammadiyah Majenang' Edu Elektrika Journal, vol. 4, no. 2, hh. 2430.

Sistem Pendidikan Nasional, 2003, Undang-Undang No. 20 Tahun 2003. Departemen Pendidikan Nasional, Jakarta.Sugiyono, 2013, Metode Penelitian Pendidikan; Pendekatan Kuantitatif, Kualitatif, dan R\&D., Alfabeta, Bandung.

Suryabrata, S 2012, Metodologi Penelitian, PT Raja Gravindo, Jakarta. 